\title{
$\mathrm{M}|\mathrm{R}| \mathrm{S}$ Internet Journal Nitride Semiconductor Research
}

\section{A GaN/4H-SiC heterojunction bipolar transistor with operation up to $300^{\circ} \mathrm{C}$}

\author{
John T Torvik ${ }^{1}$, M. Leksono ${ }^{1}$, J. I. Pankove ${ }^{1}$ and B. Van Zeghbroeck ${ }^{2}$ \\ ${ }^{1}$ Astralux Inc., \\ ${ }^{2}$ University of Colorado,
}

(Received Tuesday, February 9, 1999; accepted Saturday, April 10, 1999)

\begin{abstract}
We report on the fabrication and characterization of GaN/4H-SiC n-p-n heterojunction bipolar transistors (HBTs). The device structure consists of an $\mathrm{n}-\mathrm{SiC}$ collector, $\mathrm{p}-\mathrm{SiC}$ base, and selectively grown $\mathrm{n}-\mathrm{GaN}$ emitter. The HBTs were grown using metalorganic chemical vapor deposition on $\mathrm{SiC}$ substrates. Selective $\mathrm{GaN}$ growth through a $\mathrm{SiO}_{2}$ mask was used to avoid damage that would be caused by reactive ion etching. In this report, we demonstrate common base transistor operation with a modest dc current gain of 15 at room temperature and 3 at $300^{\circ} \mathrm{C}$.
\end{abstract}

\section{Introduction}

The wide bandgap semiconductors $\mathrm{GaN}$ and $\mathrm{SiC}$ hold great promise for high temperature and high power electronics. This is due to their attractive material properties, such as high breakdown fields, high thermal conductivities, high saturated electron velocities, and adequate electron mobilities. [a] [3] [4] By growing $\mathrm{GaN}$ directly on $\mathrm{SiC}$ one can make n-p heterojunctions. [5], [6] Adding a $\mathrm{SiC}$ collector layer led to the demonstration of high temperature and high power GaN/6HSiC HBTs. [7], [8] These transistors exhibited an extraordinarily high room temperature current gain of $>10^{6}$ and were able to operate at $535^{\circ} \mathrm{C}$ with a gain of 100. However, in more recent work this performance could not easily be reproduced due to the presence of a deep defect level in the p-type 6H-SiC. [9] The possibility of obtaining higher quality $4 \mathrm{H}-\mathrm{SiC}$ than $6 \mathrm{H}-\mathrm{SiC}$ seemed appealing due to the larger bandgap energy and superior electron mobility (especially along the $\mathrm{C}$-axis). In this paper, we report on $\mathrm{GaN} / \mathrm{SiC}$ HBTs using the $4 \mathrm{H}$ polytype.

\section{Device design}

There are several design issues worth mentioning. Making HBTs from GaN/4H-SiC instead of using GaN/6H$\mathrm{SiC}$ reduces the expected current gain $(\beta)$, because the emitter injection efficiency $\left(\gamma_{\mathrm{E}}\right)$ has a strong dependence on the difference in the bandgap energies $\left(\Delta \mathrm{E}_{\mathrm{g}}\right)$ as shown in Equation (1). [10]

$$
\begin{gathered}
y_{E}=\frac{1}{1+\frac{I_{p, E}}{I_{n, E}} \text { and }} \\
\frac{I_{p, E}}{I_{n, E}}=\frac{x_{B} D_{p, E} N_{B}}{L_{p, E} D_{n, B} N_{E}} \frac{N_{c, E} N_{v, E}}{N_{c, B} N_{v, B}} e^{-\frac{\Delta E_{\mathrm{E}}}{k T}}
\end{gathered}
$$

where $I_{p, E}$ and $I_{n, E}$ are the emitter hole and electron currents, $\mathrm{L}_{\mathrm{p}, \mathrm{E}}$ is the hole diffusion length in the emitter, $\mathrm{X}_{\mathrm{B}}$ is the quasi-neutral base width, $\mathrm{N}_{\mathrm{E}}$ and $\mathrm{N}_{\mathrm{B}}$ are the doping densities in the emitter and base, $\mathrm{D}_{\mathrm{E}}$ and $\mathrm{D}_{\mathrm{B}}$ are the diffusion constants in the emitter and the base, and $\mathrm{N}_{\mathrm{c}}$ and $\mathrm{N}_{\mathrm{v}}$ are the effective density of states at the conduction and valence band-edges, respectively. Although $\Delta \mathrm{E}_{\mathrm{g}}$ is smaller for $\mathrm{GaN} / 4 \mathrm{H}-\mathrm{SiC}$ at $0.2 \mathrm{eV}$ than for GaN/ $6 \mathrm{H}-\mathrm{SiC}$ at $0.4 \mathrm{eV}$, the theoretical current gain can still be large for well-designed HBTs. First order calculations, using an electron mobility in the base of $100 \mathrm{~cm}^{2} / \mathrm{V}$-s and a minority carrier life time in the base of $10 \mathrm{~ns}$, indicate that the current gain is limited by the base transport to 128 . The emitter efficiency was calculated at 0.9997 so that the device is not expected to be limited by the hole injection into the emitter. Furthermore, the large $\Delta \mathrm{E}_{\mathrm{g}}$ allows the $\mathrm{p}-\mathrm{SiC}$ base to be heavily doped, which decreases the base resistance and the sensitivity to the Early effect without compromising the emitter efficiency (see Equation (1)). The heavily doped base is 
also practical for making tunneling contacts to the ptype $\mathrm{SiC}$. [11]

Recently, an AlGaN/GaN HBT was demonstrated with a dc current gain of 3 at room temperature. [12] However, our hybrid $\mathrm{GaN} / \mathrm{SiC}$ approach with an indirect bandgap p-SiC base has an intrinsic advantage over a direct bandgap p-GaN base. This is because the minority carrier lifetime is much longer in $\mathrm{SiC}$ compared to $\mathrm{GaN}$, which means a higher base transport factor. Furthermore, by using commercially available $\mathrm{p}-\mathrm{SiC}$ one avoids the current material difficulties associated with $\mathrm{p}$ GaN. [12] Admittedly, growing GaN/SiC junctions with good electrical characteristics is probably more challenging than in the AlGaN/GaN materials system. The growth is especially important since great care must be taken to minimize minority carrier recombination at the emitter-base heterojunction to obtain high emitter injection efficiency. [13]

\section{Device Fabrication}

A cross sectional schematic of the GaN/SiC HBT structure is shown in Figure 1.

The $\mathrm{SiC}$ epi-layers used in this study were grown by MOCVD on commercial 4H-SiC Si-face $\left(\mathrm{n} \sim 10^{18} \mathrm{~cm}^{-3}\right)$ substrates. The $\mathrm{SiC}$ part of the HBT consists of a $1-\mu \mathrm{m}-$ thick n-type $\left(5 \times 10^{17} \mathrm{~cm}^{-3}\right) \mathrm{SiC}$ collector with a 0.225 $\mu \mathrm{m}$-thick p-type base layer. The p-type doping concentration $(\mathrm{Al})$ is $\mathrm{N}_{\mathrm{A}}=5 \times 10^{19} \mathrm{~cm}^{-3}$, but the hole concentration was not measured in these samples. Device isolation was provided by reactive ion etching (RIE) to form a trench around each device. RIE was performed with Freon $14\left(\mathrm{CF}_{4}\right)$ at $35 \mathrm{mT}$ with a $20 \mathrm{sccm}$ gas flow rate at a power density of $0.14 \mathrm{~W} / \mathrm{cm}^{2}(100 \mathrm{~W}$ in our system). A 70-nm-thick $\mathrm{SiO}_{2}$ layer was then grown by thermal wet oxidation at $1175^{\circ} \mathrm{C}$. This $\mathrm{SiO}_{2}$ layer provides collector-base junction passivation in addition to serving as a mask for selective area $\mathrm{GaN}$ growth. [14] The emitter patterns are transferred to the $\mathrm{SiO}_{2}$ using standard photolithography and an HF etch. Next, the $\mathrm{GaN}$ emitter was grown by MOCVD. [13] The emitters are typically $\sim 0.5-\mu \mathrm{m}$-thick and unintentionally doped. Note that low-temperature GaN or AlN nucleation (buffer) layers were not used. An SEM picture exhibiting a selectively grown $\mathrm{GaN}$ emitter finger is shown in Figure 2.

$\mathrm{Ti} / \mathrm{Au}$ and $\mathrm{Al} / \mathrm{Ti} / \mathrm{Au}$ contacts were formed to the $\mathrm{n}$ $\mathrm{GaN}$ emitter and the p-SiC base, respectively, using the standard photoresist lift-off technique. A Ni/Au bi-layer was used as a large area $\mathrm{n}-\mathrm{SiC}$ back contact. Pictures of two completed devices are shown in Figure 3.

Current-voltage (I-V) measurements were performed using a probe station and an HP4145B semicon- ductor parameter analyzer. The high temperature measurements were made using a copper sample holder heated by a hotplate. Convection cooling was avoided by enclosing the copper block and sample in a metal container covered by glass microscope slides with holes for the probe tips. The temperature was measured using a thermocouple that was calibrated using Timpilsticks ${ }^{\circledR}$ and by melting various metals.

\section{Results and Discussion}

Typical room temperature common base I-V characteristics for the GaN/4H-SiC HBTs are shown in Figure 4. This particular device had one $10 \mu \mathrm{m}$ x $100 \mu \mathrm{m}$ emitter finger as shown in Figure 3 (left).

The emitter current was stepped at $1 \mathrm{~mA}$ increments. The saturated collector current is nearly equal to the emitter current, with a maximum dc current gain $\left(\beta=\mathrm{I}_{C}\right)$ $\mathrm{I}_{\mathrm{B}}$ ) of 15 at room temperature. The onset of collector current is slightly above $-3 \mathrm{~V}$, which corresponds roughly to the built-in potential in the $4 \mathrm{H}-\mathrm{SiC}\left(\mathrm{E}_{\mathrm{g}}=3.2 \mathrm{eV}\right)$ collector-base p-n junction at these doping levels. Breakdown in these devices occurs above $15 \mathrm{~V}$. As expected, due to the heavily doped base, the Early voltage is too large to measure accurately. Common emitter operation was not obtained in these HBTs, probably due to the large voltage dependent leakage current in the collectorbase junction. Next, we will discuss the electrical characteristics of the individual collector-base and emitterbase pn junctions.

Typical room temperature I-V characteristics for the base-emitter heterojunction (broken line) and the basecollector junction (solid line) are shown in Figure 5.

The collector-base junction exhibits significant reverse leakage and forward recombination or tunneling currents. However, there is a kink in the I-V trace at about $+3 \mathrm{~V}$ volts indicating the presence of forward injection current. No meaningful ideality factor or saturation current was extracted. Similar conclusions can be drawn for the emitter-base heterojunction. The voltage dependent reverse leakage current is significant, and the forward current onset voltage is too low for a pn junction with a built in potential of $\sim 3 \mathrm{~V}$ indicating recombination or tunneling. Both tunneling and recombination are loss mechanisms that would explain the low gain in these HBTs.

Gummel plots for the HBTs measured at room temperature and at $300^{\circ} \mathrm{C}$ are shown in Figure 6 and Figure 7 , respectively.

Note that there is significant leakage current present at low emitter-base voltages (lower than the built-in potential). However, this was also observed in the early GaN/6H-SiC HBTs, which had leaky collector-base junctions. More ideal Gummel plots were obtained by 
improving the electrical characteristics in the collectorbase junctions. [15] At high $\mathrm{V}_{\mathrm{BE}}$ the current is dominated by series resistance. Even so, the devices exhibit a dc current gain of 15 at room temperature and 3 at $300^{\circ} \mathrm{C}$. The current gain was measured at $\mathrm{V}_{\mathrm{BE}}=5 \mathrm{~V}$. It is worth noting that by removing the base contact no collector current was observed eliminating the possibility of a short through the device. In other words, a small base current is required for transistor operation.

The dc current gain at $\mathrm{V}_{\mathrm{BE}}=5 \mathrm{~V}$ was measured as a function of temperature and plotted in an Arrhenius fashion as shown in Figure 8.

The current gain decreases with increasing temperature, and the extracted activation energy is $0.07 \mathrm{eV}$. However, the temperature dependence of the gain indicates that the gain is not limited by the emitter efficiency, as a much larger gain and a larger temperature dependence $\left(\mathrm{E}_{\mathrm{A}}=\Delta \mathrm{E}_{\mathrm{g}}=0.2 \mathrm{eV}\right)$ would be expected. Instead it can be explained by the temperature variation of the mobility, which leads to a temperature variation of the diffusion constant and transit time in the base.

Assuming uniform current injection across the $(10 \mathrm{x}$ $100 \mu^{2}$ ) emitter-base junction results in a maximum current density of $500 \mathrm{~A} / \mathrm{cm}^{2}$ at $15 \mathrm{~V}$. The corresponding power density is therefore $7.5 \mathrm{~kW} / \mathrm{cm}^{2}$.

\section{Conclusions}

We have demonstrated the first $4 \mathrm{H}-\mathrm{SiC} / \mathrm{GaN}$ HBT structure and have successfully operated the device between room temperature and $300^{\circ} \mathrm{C}$. The devices could sustain a maximum current density of $500 \mathrm{~A} / \mathrm{cm}^{2}$ at power density of $7.5 \mathrm{~kW} / \mathrm{cm}^{2}$. The devices have some obvious deficiencies including large leakage currents and series resistances. Nevertheless we were able to demonstrate transistor action in those devices, which implies that there is no significant barrier for electrons flowing from the emitter into the base. $6 \mathrm{H}-\mathrm{SiC} / \mathrm{GaN}$ HBTs have been reported in the past with much larger current gain. Despite the lower gain of the $4 \mathrm{H}-\mathrm{SiC} / \mathrm{GaN}$, we believe these devices to be distinctly superior to $6 \mathrm{H}-\mathrm{SiC} / \mathrm{GaN}$ device because of the higher electron mobility along the $\mathrm{C}$-axis and the smaller temperature dependence of the current gain. These properties will lead to a larger transit frequency and operation over a wider temperature range in a microwave circuit.

Next, we need to improve the base (p-SiC) contacts and reduce the $\mathrm{n}-\mathrm{SiC}$ collector doping density. Furthermore, a reduction of the leakage current in the large area base-collector junction, and a reduction of the recombination/tunneling current in the emitter base heterojunction is expected to facilitate improved transistor characteristics and common emitter operation.

\section{ACKNOWLEDGMENTS}

This work was supported in part by BMDO/ DSWA and ONR. The authors are grateful to Dr. G.W. Eldridge for supplying the SiC, Dr. L.B. Rowland, Mr. R. Waters and Dr. C.H. Qiu for valuable discussions. Furthermore, the authors would like to thank the optoelectronics-manufacturing group at NIST (Boulder) for the use of cleanroom facilities through a Cooperative Research And Development Agreement (CRADA).

\section{REFERENCES}

[a] See for example: [1] [2]

[1] G. Pensl, H. Morkoc, B. Monemar, and E. Janzen (Editors), Proc. $7^{\text {th }}$ int. conf. on SiC, III-nitrides and related materials, Trans Tech Publications, Enfield (USA).

[2] M.A. Capano and R.J. Trew (Editors) Mat. Res. Soc. Bulletin, 22 (3), pp. 19-56, (1997)

[3] J.I Pankove and T.D. Moustakas (Editors), Semiconductors and Semimetals, Vol. 50 Gallium Nitride (GaN) I, Academic Press, New York (1997).

[4] J.I Pankove and T.D. Moustakas (Editors), Semiconductors and Semimetals, Vol. 57 Gallium Nitride (GaN) II, Academic Press, New York (1998)

[5] John T. Torvik, M. Leksono, J. I. Pankove, B. Van Zeghbroeck, H. M. Ng, T. Moustakas, Appl. Phys. Lett. 72 , 1371 (1998).

[6] NI Kuznetsov, AE Gubenco, AE Nikolaev, YuV Melnik, MN Blashenkov, IP Nikitina, VA Dmitriev, Mater. Sci. Eng. B 46, 74-78 (1997).

[7] "High-temperature $\mathrm{GaN} / \mathrm{SiC}$ heterojunction bipolar transistorwith high gain", J.I. Pankove, S.S. Chang, H. C. Lee, R. Molnar, T.D. Moustakas, B. Van Zeghbroeck, Proc. IEDM, p. 389-392, San Francisco, CA (1994)

[8] J. I. Pankove, M. Leksono, S. S. Chang, C. Walker, B. Van Zeghbroeck, MRS Internet J. Nitride Semicond. Res. 1, 39 (1996).

[9] John T. Torvik, C. H. Qiu, M. Leksono, J. I. Pankove, Appl. Phys. Lett. 72, 945 (1998).

[10] S.M. Sze, Physics of Semiconductor Devices, Wiley, New York, 1981, p. 140-144.

[11] S.M. Sze, Physics of Semiconductor Devices, Wiley, New York, 1981, p. 517.

[12] "A first look at AlGaN/GaN HBTs", L. McCartney, P. Kozodoy, M. Rodwell, S. DenBaars, and U. Mishra, Compound Semiconductor, Vol. 4, No.8, November 1998

[13] J. T. Torvik, M. W. Leksono, J. I. Pankove, C. Heinlein, J. K. Grepstad, C. Magee, J. Electron. Mater. 28, 234-239 (1999).

[14] Y. Kato, S. Kitamura, K. Hiramatsu, N. Sawaki, J. Cryst. Growth 144 , 133 (1994).

[15] "High-temperature and high-gain GaN/SiC heterojunction bipolartransistors", S.S. Chang, Ph.D. dissertation, University of Colorado, 1996 


\section{FIGURES}

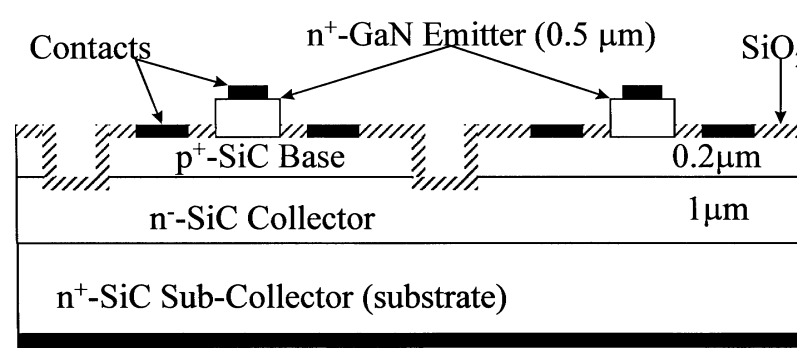

Figure 1. A cross section of two adjacent GaN/SiC HBTs.

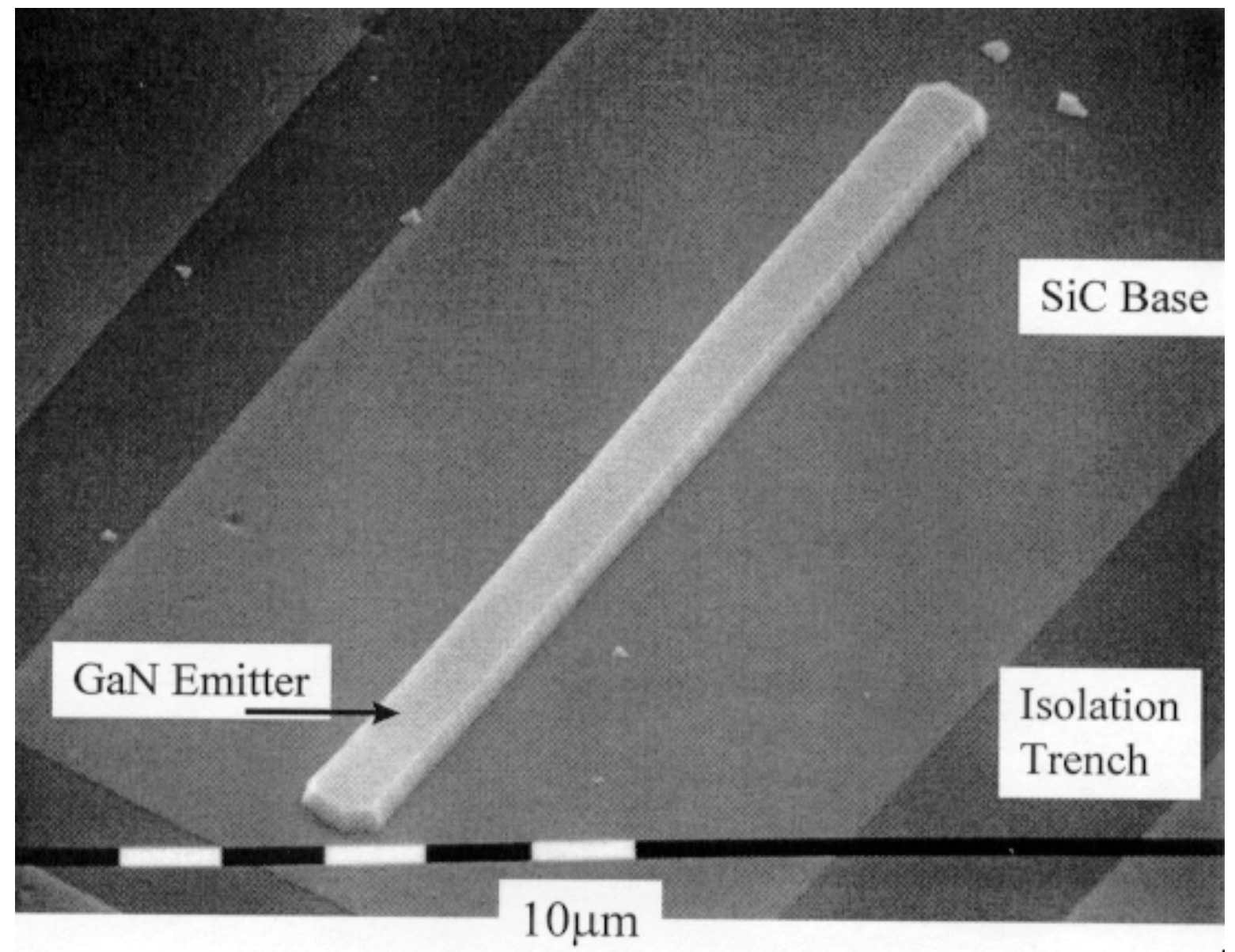

Figure 2. An SEM picture of a GaN emitter finger grown on patterned $\mathrm{SiO}_{2} / \mathrm{p}-\mathrm{SiC} / \mathrm{n}-\mathrm{SiC}$ using $\mathrm{MOCVD}$. 

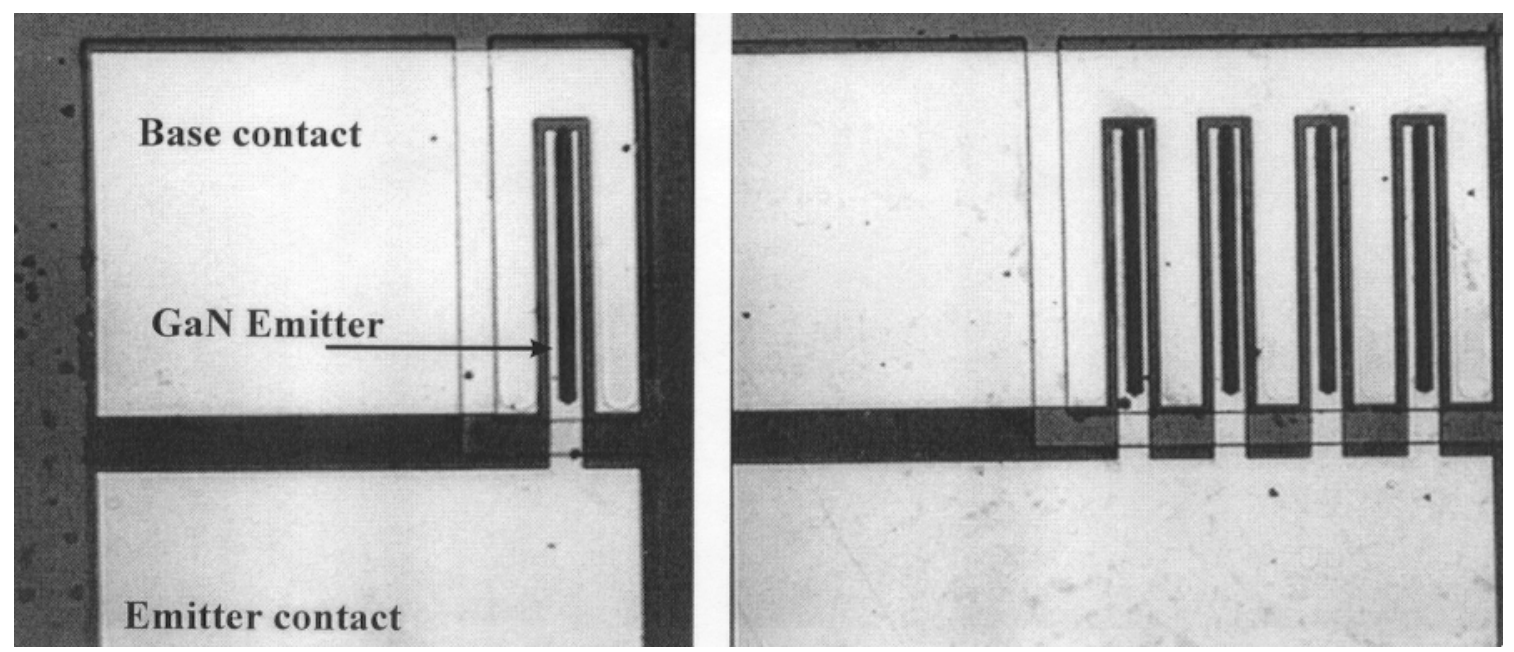

Figure 3. Pictures of two completed GaN/SiC HBT structures with one GaN emitter finger (left) and four GaN emitter fingers (right). The emitter widths in both devices are $10 \mu \mathrm{m}$.

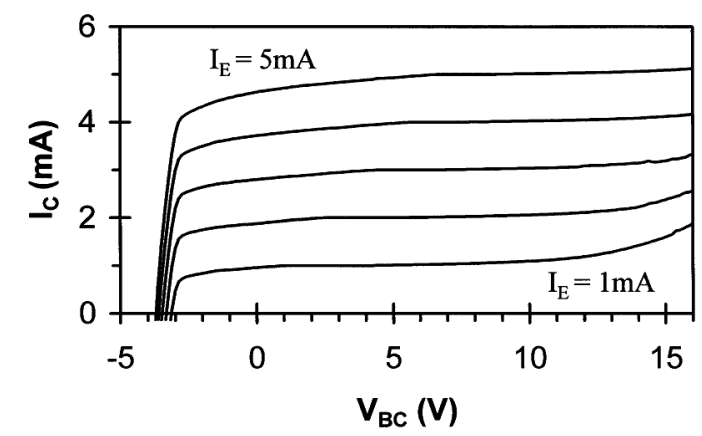

Figure 4. Room temperature common base I-V characteristics for a GaN/4H-SiC HBT. The emitter current is stepped in $1 \mathrm{~mA}$ increments from $1 \mathrm{~mA}$.

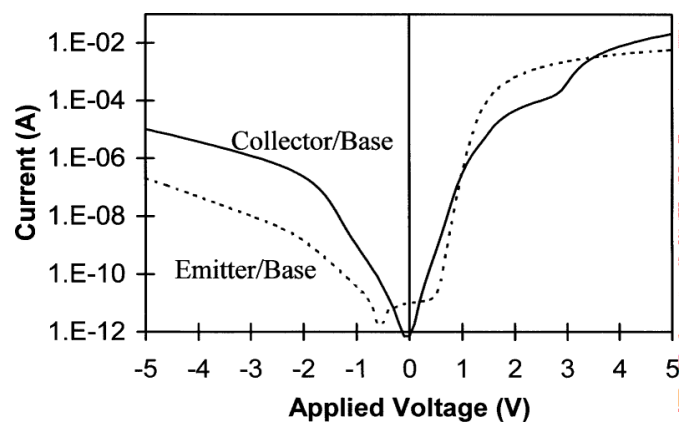

Figure 5. Room temperature I-V characteristics for the baseemitter heterojunction (broken line) and the base-collector junction (solid line).

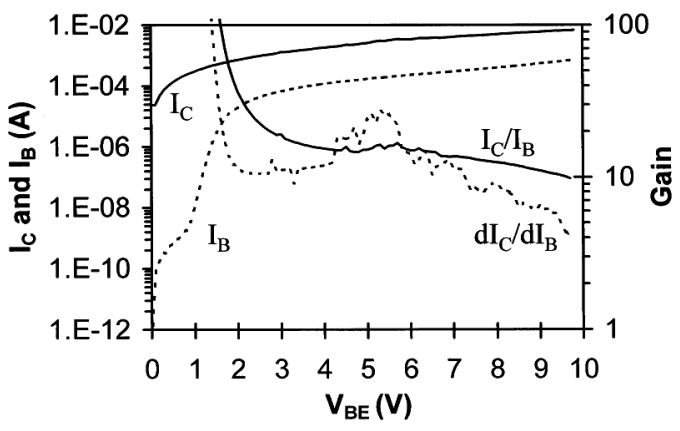

Figure 6. Gummel plot measured at room temperature from an HBT with one GaN emitter finger $\left(\mathrm{A}=10 \times 100 \mu \mathrm{m}^{2}\right)$.

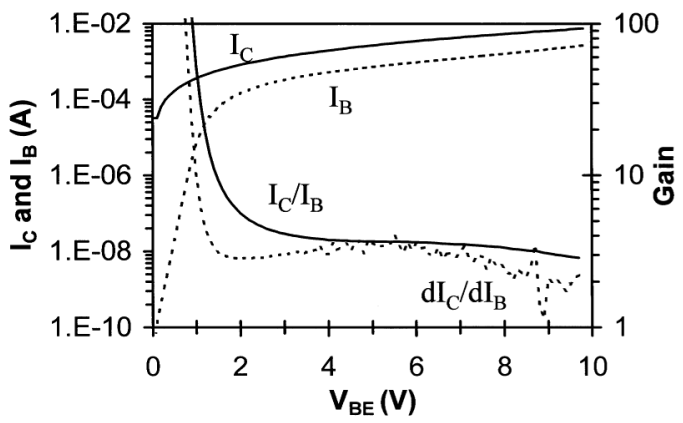

Figure 7. Gummel plot measured at $300^{\circ} \mathrm{C}$. 


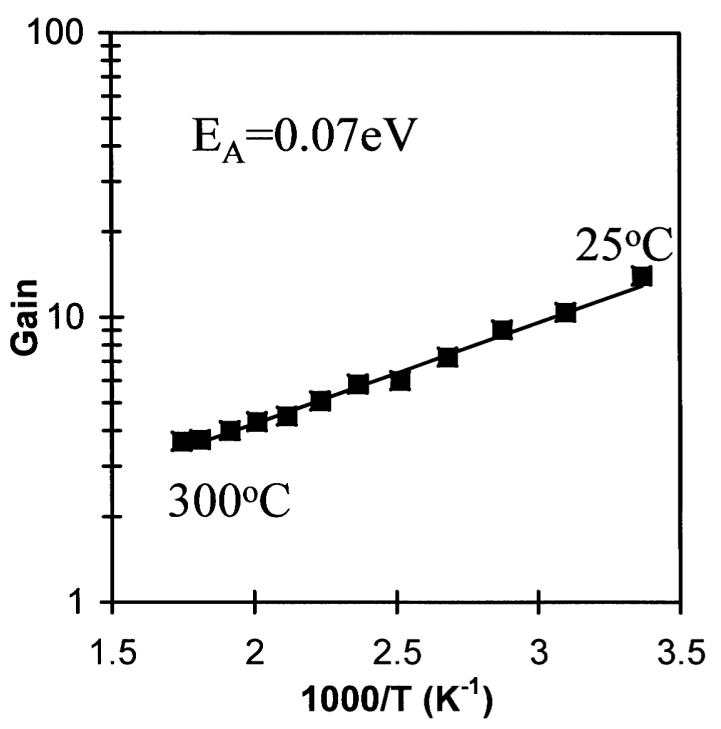

Figure 8. Arrhenius plot of the dc current gain measured at $\mathrm{V}_{\mathrm{BE}}=5 \mathrm{~V}$. The extracted activation energy is $0.07 \mathrm{eV}$. 